\title{
A Better Carbon Footprint Label
}

\author{
Thøgersen, John; Nielsen, Kristian S.
}

Document Version

Accepted author manuscript

Published in:

Journal of Cleaner Production

DOI:

10.1016/j.jclepro.2016.03.098

Publication date:

2016

License

CC BY-NC-ND

Citation for published version (APA):

Thøgersen, J., \& Nielsen, K. S. (2016). A Better Carbon Footprint Label. Journal of Cleaner Production, 125, 8694. https://doi.org/10.1016/j.jclepro.2016.03.098

Link to publication in CBS Research Portal

\section{General rights}

Copyright and moral rights for the publications made accessible in the public portal are retained by the authors and/or other copyright owners and it is a condition of accessing publications that users recognise and abide by the legal requirements associated with these rights.

Take down policy

If you believe that this document breaches copyright please contact us (research.lib@cbs.dk) providing details, and we will remove access to the work immediately and investigate your claim.

Download date: 26. Apr. 2023
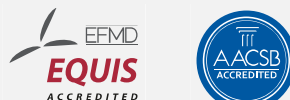


\section{A Better Carbon Footprint Label John Thøgersen and Kristian S. Nielsen}

Journal article (Postprint version)

Cite: A Better Carbon Footprint Label. / Thøgersen, John; Nielsen, Kristian S. In: Journal of Cleaner Production, Vol. 125, 07.2016, p. 86-94.

DOI: http://dx.doi.org/10.1016/j.jclepro.2016.03.098

Uploaded to Research@CBS: June २०16

(C) 2016. This manuscript version is made available under the CL-BY-NC-ND 4.0 license http://creativecommons.org/licenses/by-nc-nd/4.0/ 


\section{A Better Carbon Footprint Label}

John Thøgersen ${ }^{a} *$ \& Kristian S. Nielsen ${ }^{b}$

* Corresponding author

${ }^{a}$ Aarhus University, School of Business and Social Sciences, Department of Management, Bartholins Allé 10, 8000 Aarhus C, Aarhus, Denmark,

Email: jbt@mgmt.au.dk

${ }^{b}$ Copenhagen Business School, Centre for Corporate Social Responsbility, Porcelaenshaven 18A, 2000 Frederiksberg, Copenhagen, Denmark,

Email:ksn.ikl@cbs.dk 


\section{Abstract}

Based on insights from behavioral economics, it is suggested to extend carbon footprint labeling with information about relative performance, using the well-known "traffic light" color scheme to communicate relative performance. To test this proposition, the impact of a carbon footprint label on Danish consumers' choice of ground coffee was tested in a 3 price levels x 3 levels of carbon emission x 3 certifying organizations $\mathrm{x} 2$ organic labeling conditions discrete choice experiment. Participants were randomly assigned to two slightly different variants of the experiment: In one condition, participants saw the original Carbon Trust label and in the other condition they saw the same label, but with traffic light colors added to communicate the product's relative performance in terms of carbon footprint. All included attributes were found to have a significant impact on consumer choices. As expected, price and carbon footprint were negatively related to choice. Further, participants preferred organic to non-organic coffee and certification by a public authority. The effect of the carbon label is significantly stronger the more environmentally concerned the consumer is. Using colors to indicate relative carbon footprint significantly increases carbon label effectiveness. Hence, a carbon footprint label is more effective if it uses traffic light colors to communicate the product's relative performance.

Keywords: Carbon footprint label; traffic light colors label; discrete choice experiment; behavioral economics 


\section{A Better Carbon Footprint Label}

\section{Introduction}

Carbon footprinting refers to the measurement of the total emission of carbon dioxide (and other greenhouse gases such as nitrous oxide and methane) caused by a particular product throughout its life cycle (Wiedmann and Minx, 2007). Based on such measurement, a carbon footprint label communicates the amount of carbon dioxide equivalents emitted during the manufacturing, distribution, use and disposal of a product (Hornibrook et al., 2015; Vanclay et al., 2011). A carbon footprint label is expected to make consumers attend to how their product choices affect greenhouse gas emissions and help them identify low-carbon alternatives (Kimura et al., 2010).

Studies have found substantial consumer interest in information regarding the carbon footprint of products (Gadema and Oglethorpe, 2011; Van Loo et al., 2014). According to a Eurobarometer survey from 2009, nearly three quarter of the adult population of EU agrees that labeling a product's carbon emissions should be mandatory in the future (European Commission, 2009). However, studies of consumer misconceptions regarding greenhouse gas emissions related to products document a need for improvements for this type of information to be effective (Gadema and Oglethorpe, 2011; Tobler et al., 2011).

Several different carbon footprint-labeling schemes have been tested around the world. In 2007, Carbon Trust - a private company set up by the UK government - introduced the world's first label to display the carbon footprint on individual products (Carbon Trust, 2012). Same year, British retailer Tesco pledged to put carbon footprint labels on its products (Boardman, 2008). Numerous products were labeled, but Tesco dropped the labeling again in 2012, blaming the amount of work involved and the lack of back-up from other retailers (Vaughan, 2012).

Most carbon labeling has taken one of three forms. The Carbon Trust label communicates the greenhouse gas emissions associated with a product throughout its life cycle. Other carbon labels communicate a commitment to emissions reduction (Upham et al., 2011). A third type communicates that the product is carbon neutral, which is typically accomplished through the retirement of carbon credits or carbon offsetting. Especially this third method has been subjected to criticism, as "carbon neutrality" can be accomplished through monetary transactions without requiring reductions in carbon emissions. However, the two former methods are also not devoid of potentially problematic features.

Awarding a company with a label for committing to a reduction target (the second form) may potentially produce a reduction in emissions (Upham et al., 2011). However, it does not help consumers to make comparisons of current product alternatives or assist them in selecting lowcarbon products, as carbon intensive products can also be awarded the label.

A drawback of the Carbon Trust labeling is that consumers are left to judge for themselves what the carbon footprint score means, and whether the product is more environmentally-friendly than other products (Kimura et al., 2010). Although many consumers know the term "carbon footprint", they rarely fully understand it (Boardman, 2008). Also, if not accompanied by other information, consumers often struggle with relating emission measurements in grams of carbon to something they understand (Hornibrook et al., 2015; Upham et al., 2011). For example, 81 percent of respondents in one study found the understanding and comparison of carbon footprint information difficult and confusing (Gadema and Oglethorpe, 2011). 
Hence, there is strong evidence that a major reason for the somewhat disappointing results of carbon footprint labeling to date (Hornibrook et al., 2015) is that the labeling is often too demanding for most consumers, who do not understand it properly, despite a positive attitude towards the labeling. Furthermore, research on other types of eco-labeling suggests that consumers' understanding of the information such a label seeks to convey, and consequently its impact on their choices, depends on subtle cues in the label's design (Heinzle and Wüstenhagen, 2012; Ölander and Thøgersen, 2014; Teisl et al., 2008). However, there is a lack of research on how the design of an eco-label may be optimized based on knowledge on common heuristics and biases in consumer decision-making, or specifically how consumers make the kind of decisions that the label aims to influence. More specifically with regard to carbon footprint labeling, there is a lack of research on how the effectiveness of such a label might be increased by optimizing its design. On this backcloth, this paper proposes and tests an improvement of a well known carbon footprint label based on insights from behavioral economics (Ölander and Thøgersen, 2014; Reisch and Sunstein, 2015; Thaler and Sunstein, 2008) and research on heuristics and biases in consumer decisionmaking and on how the human brain functions (Kahneman, 2011). The core assumption is that the label's effectiveness can be improved by making its key information more intuitively understandable to the average consumer.

Specifically, strong evidence support the proposition that "everything is relative" (Kahneman, 2011) to the average person. Hence, in order to make emission measurements more intuitively understandable to consumers, a carbon footprint label should communicate the relative performance of the product at hand, in addition to the absolute emissions. Because it is well-known and used in a similar way in many other contexts (e.g., the European energy label or the UK's "traffic light" label for health-related aspects of food products), it seems obvious to extend a carbon label with traffic light colors communicating whether products' associated carbon emissions, compared to its product category, are relatively low (green), high (red) or about average (yellow). Specifically, we propose and test a version of the Carbon Trust labeling scheme which is extended by a three-tier rank-order, where all products in a category are ranked based on their carbon footprint, and traffic light colors are used to communicate how well the product performs relative to others in the same product category.

By labeling all products in a category, a three-tier rank order is also an extension compared to the binary approach that most eco-labels use, where products are either awarded the label or not. Labels such as EU's Flower and the Nordic Swan inform consumers that products awarded this label are to be preferred over non-labeled products in terms of environmental impacts. Hence, in these cases it is communicated that the labeled product is particularly good, from an environmental point of view. However, it is an obvious drawback of this binary system that consumers are not informed whether some of the non-labeled products are particularly bad (Grankvist et al., 2004). Consumers get no help if they want to compare non-labeled products - the vast majority - in terms of environmental performance.

The reverse of positive labeling is negative labeling, aiming to make consumers refrain from purchasing the most environmentally harmful products. There is evidence suggesting that consumers who are not willing to pay a premium for better-than-average sustainability products may still be willing to pay to avoid worse-than-average products (Prakash, 2002; Van Dam and De Jonge, 2015). This effect has been explained by negativity bias (Van Dam and De Jonge, 2015). For example, prospect theory is based on the assumption that most people are loss averse and therefore negative information has a greater effect on their judgments and behavior than neutral or positive information (Kahneman and Tversky, 1979). In addition, there is evidence that people attend to negative information more often and for a longer period of time than to positive information (Fiske, 
1980; Ito et al., 1998). Specifically, studies by Grankvist et al. (2004) and Van Dam and De Jonge (2015) found that labeling the least environmentally friendly alternatives is more effective in changing consumer behavior than positive labeling of environmental friendly products. This research suggests that negative carbon labeling might influence consumer choices more than positive labeling.

When using traffic light colors to communicate the product's relative performance, a green carbon footprint label functions similarly to a binary eco-labeling scheme, where consumers with some basic knowledge of eco-labels associate the labeled product with the implicit message "this product is 'better' or less negative for the environment than the average product" (Grankvist et al., 2004). However, compared to a binary eco-label, a traffic colored carbon footprint label has the advantage that also the inferior ("red") products in a category are labeled, not only the superior ("green") products.

In practice, traffic light colors have until now been used in two different ways for product labeling: A simple three-tier labeling for communicating the healthfulness of food products (e.g., in the UK) and a more complex seven-tier labeling for appliances and cars (in the EU). For everyday commodities, a simpler labeling system is usually preferred because of consumers' lowinvolvement when making this kind of choices and ample empirical evidence showing that they make this kind of choices extremely fast in the store (e.g., Thøgersen et al., 2012). Hence, it seems more likely that consumers will understand and use a simpler than a more complex label when doing their everyday shopping (Grunert and Wills, 2007). Therefore, we also propose, and test, the simplest, three-tier version of the traffic light labeling for the carbon footprint labeling of everyday commodities.

\section{Hypotheses}

The reviewed research suggests that a carbon footprint label has the potential to influence consumers' product choices and direct them towards low-carbon products and away from carbonintensive products. The strength of this influence may vary between countries, for example, depending on the level of climate- or more general environmental concern in the country and consumers' familiarity with this type of label, but the label improvement that we test is a response to a basic human condition: our limited cognitive capacity (Kahneman, 2011), and is hence not limited to a specific national context.

For an ecolabel to influence consumer choices, key prerequisites are that consumers are aware of the label, know what it means, and are motivated to take the information it conveys into account when making choices (Thøgersen, 2005). In the present study, we exposed the participants to a hypothetical carbon footprint label and briefly explained what it means, before testing its impact on their choices. Hence, participants in this study have been made aware of the tested carbon footprint label and can be assumed to know what it means. Also, previous research suggests that most consumers in the studied context are motivated to take the information such a label conveys into account when making choices (European Commission, 2009). We hypothesize that, when these conditions are fulfilled, a carbon footprint label influences consumer choices.

H1.In a context where many people are concerned about carbon emissions, when consumers are aware of a carbon footprint label on everyday grocery products and know what it means, such a label will influence consumer choices, shifting choices in the direction of low-carbon products. 
Carbon footprint labeling is a help for consumers who want to reduce their carbon footprint.

Environmental concern varies across individuals in any society. If they have understood the label correctly, it is only environmentally concerned consumers that are motivated to let it influence their choices. It follows that the effect of a carbon footprint label on consumers' choices should be stronger the more environmentally concerned they are. Hence, it is hypothesized that:

H2.A carbon footprint label will influence consumers' choices more the more environmentally concerned they are.

The reviewed research further suggests that the effect of a carbon footprint label on consumer choices is reduced because the average consumer finds the label confusing and incomprehensible. It follows that the effect of such a label could be amplified if its core message was made easier to understand. One way of making carbon footprinting more intuitively understandable to consumers would be to communicate the relative performance of the product within its category, for example by means of the well known traffic light color ranking system. Hence, it is hypothesized that:

H3. The impact of a carbon footprint label on consumer choices of an everyday grocery product can be amplified by extending the label with a "traffic light ranking," communicating the product's relative carbon footprint, compared to other products in the same category.

\section{Method}

The hypotheses were tested by means of a discrete-choice experiment, which was administered by means of an online survey (Qualtrics), participants being a convenience sample of Danish consumers answering the survey in their own pace and at a place of their own choice.

\subsection{Data Collection and Sample}

The questionnaire was distributed through Facebook and email using snowball sampling. A total of 148 individuals completed the questionnaire of which four were excluded because they had not bought coffee at all the last three years and seven were excluded because they chose the none-ofthese option five times or more. This resulted in an effective sample of 137 respondents, randomly allocated to either Group $1(n=71)$ or Group $2(n=66)$. Even if relatively small, the sample size for each group is above the recommended minimum for choice-based conjoint analysis (Marshall et al., 2010). Socio-demographics of the sample are shown in Table 1. It appears that the participants in the study is a broad sample of Danish consumer with an over-representation of young, welleducated individuals. With this convenience sample, parameter estimates cannot be assumed representative of the Danish population. However, for testing hypotheses based on a random allocation of participants to experimental groups, this is not usually considered a problem (Evans and Rooney, 2014).

\section{[Insert Table 1 around here]}

\subsection{Measures}

The questionnaire opened with a few demographic items and a screening question - participants who had not purchased coffee the last three years were excused. Then followed questions about the consumption of coffee and then the discrete-choice experiment. After the choice experiment, questions about environmental concern and about other issues not pertinent to the present paper were asked.

Environmental concern was measured with five items taken from Thøgersen et al. (2010), using a 7point Likert scale with the end-point labels "strongly disagree" and "strongly agree": (1) I am 
concerned about the development of the global environment, (2) I feel it is a moral obligation to use environment-friendly products, (3) It concerns me that people do not care enough for the environment, (4) I have changed from one brand to another for the sake of the environment, (5) I often buy eco-labeled products for the sake of the environment. The environmental concern index produced by averaging the responses to these five items has excellent construct reliability $($ Cronbach's Alpha $=.85)$.

\subsection{Discrete-Choice Experiment}

A discrete choice experiment was employed to test the hypotheses (Johnson et al., 2013). A discrete choice experiment simulates a buying situation where consumers choose between product alternatives from a restricted product set (Sammer and Wüstenhagen, 2006). The product alternatives vary on various product attributes, which forces participants to make tradeoffs between attributes. Hence, choices reveal participants' preferences and the researcher can calculate the relative weight of included attributes on participants' product evaluation and choices (De Pelsmacker et al., 2006).

Ground coffee was chosen as the product for the experiment due to its widespread use in the studied population and its environmental properties. Coffee is produced outside Europe and therefore has to be transported long distances to reach Danish consumers. Hence, in addition to the production method, the transportation distance and mode can have profound impact on the environmental friendliness of a coffee product. At the time of the data collection, organic ground coffee had a market share of around 7 percent in Denmark (Økologisk Landsforening, 2014), which suggests that a sizeable group of Danish consumers consider environmental performance in their choice of a coffee product. The organic label does not take carbon emissions into account so adding a carbon label would also provide better disclosure of the product's environmental performance.

Discrete-choice experiments typically involve the following steps: decision on product attributes, specification of attribute levels, and visual presentation of choice alternatives to respondents (Verma et al., 2004). All attributes that might help differentiate the product should be considered, but cognitive feasibility and the practical limitations of an experimental design limit the eventual number of attributes included in the study (Marshall et al., 2010). Not only attributes, but also attribute levels should be chosen that are realistic and meaningful to the respondents (Sammer and Wüstenhagen, 2006). In preparation for the present study, two focus group interviews were conducted with consumers from the target population in order to secure that included attributes were indeed realistic and meaningful. The final attributes and levels are reported in Table 2.

\section{[Insert Table 2 around here]}

Because the number of attribute levels can inflate the importance of an attribute when the number varies, the ideal discrete-choice experiment has the same number of levels across attributes (symmetry, cf. Orme, 2003). In the present experiment, complete symmetry could not be obtained because the organic label only has two levels whereas all other attributes have three. This may lead to a slight underestimation of the relative impact of the organic label on choices. However, since this impact is not the main focus of the present study, we do not discuss it any further.

The price levels were determined based on a store check, reflecting a realistic price range in the studied market at the time of the study. In Denmark, organic coffee is either labeled with the EU Organic label, the Danish Organic label, or both. Since the Danish Organic label is better known by Danish consumers, we used this label here.

Data from the Danish Ministry of Food, Agriculture and Fisheries were used to determine the neutral reference point of the carbon label (Ministeriet for Fødevarer Landbrug og Fiskeri, 2014), 
which was set to $150 \mathrm{~g} \mathrm{CO} 2$ for a standard package of ground coffee. There is no fixed rule for what should be considered a "high" or a "low" level for the definition of the red and the green "traffic light" category. For the experiment, it was important to choose cut-off levels that are both considered realistic and meaningful by the participants. We judged that 30 percent deviation from the average emission level would be sufficient to meaningfully define "high" and "low" and at the same time not so big as to be considered unrealistic. Hence, we defined the red/green categories as: "compared to other products of the same type, the CO2-emission of this product is 30 percent or more higher/lower than average". The $\mathrm{CO} 2$-emission associated with the yellow color was described as "about average". Consistent with these cut-off levels, the absolute low/high levels of $\mathrm{CO} 2$ emission for a standard package of ground coffee were set at $90 \mathrm{~g}$ and $210 \mathrm{~g}$. It is important to emphasize that the aim of our study is not to test whether these thresholds for being classified in the high and low categories are optimal or not. The experimental results will show if the chosen cut-off levels are indeed perceived as realistic and meaningful by participants. Where to set these cut-offs levels in practice is obviously an important question, which should be settled based on both behavioral and technical expertise. This study only provides evidence regarding the principle: whether adding information about the relative carbon footprint of a product (in the form of traffic light colors), in addition to the amount of carbon emitted through the product's lifecycle, makes the label more intuitively understandable for common consumers and therefore more effective, compared to the original idea of just reporting the latter.

As eco-labels can be certified by a governmental agency, a nongovernmental organization, or a private company, three plausible certification organizations were identified - one within each of these three categories. Miljømærkning Danmark is responsible for the Danish certification of the Nordic Swan and the EU Flower and was therefore chosen as the governmental agency. Coop is the largest retail chain in Denmark and among the most progressive in taking measures to facilitate environmentally friendly consumer choices. Therefore, it was assumed that it would be credible to participating consumers that Coop might introduce a carbon-labeling scheme in Denmark. WWF was one of the founders of the Marine Stewardship Council (MSC), which is responsible for the MSC eco-label on seafood products, and we therefore judged that participating consumers would find it credible that they might also introduce a carbon label.

To reduce the complexity of the choice experiment, a number of important coffee attributes were not varied, such as brand, taste, and country of origin. Instead, the market-leading brand, Merrild Café Noir, was chosen as a constant in the product descriptions (Berlingske Business, 2012). To reduce the risk that respondents would refrain from making a selection from the choice set due to a negative attitude towards this particular brand, it was stated in the questionnaire that, in case they did not normally purchase this brand, they should instead imagine their most preferred brand.

\subsection{The choice tasks}

Given the number of attributes and attribute levels, a full factorial design would require $54(3 \times 3 \times$ $3 \times 2$ ) combinations, which was expected to be too exhausting to participants. Therefore, a fractional factorial design was created including 27 combinations, which were divided to nine choice tasks, each containing three product profiles, in accordance with prior research and recommendations (Marshall et al., 2010). The design adhered to the principles of minimal (level) overlap, level balance, and orthogonality (Kuhfeld, 2005; Orme, 2003; Rose and Bliemer, 2009). Level overlap refers to the number of times a level is present within the same choice task. This number should be minimized to allow an efficient estimation of the main effects. A design is balanced when each level appears an equal number of times for each attribute. Design orthogonality concerns the correlation structure between the attributes of a design. An orthogonal design aims to 
minimize the correlation between the attribute levels in the choice tasks to secure that the preference for each attribute level can be measured independently.

The choice tasks were presented in randomized order to reduce the likelihood of order bias (Hensher et al., 2005). A none-of-these option was included in each choice task to make the choice tasks more realistic and the experience more pleasant, as the respondent was not forced to select an unacceptable product profile (Johnson and Orme, 2003).

\subsection{The label design experiment}

To test the effects of extending the carbon footprint label with a traffic light color ranking, respondents were randomly assigned to two groups - Group 1 and Group 2 - completing a slightly different choice experiment. Group 1 was presented with Carbon Trust's original black carbon footprint label, indicating the CO2-emissions of the given product in grams $(90 \mathrm{~g}, 150 \mathrm{~g}$, or $210 \mathrm{~g})$. Group 2 was presented with the same choice tasks as Group 1, except that the carbon footprint label took the color of red $(210 \mathrm{~g})$, yellow $(150 \mathrm{~g})$, or green $(90 \mathrm{~g})$ depending on the product's CO2emissions. All product profiles were presented on the same coffee package (see Figure 1).

[Insert Figure 1 around here]

\section{Results}

The choice modeling was done by means of conditional logistic regression using SAS JMP 12. By default, JMP base the parameter estimates on the Firth bias-corrected maximum likelihood estimators, which are considered more accurate than MLEs without bias correction (SAS Institute Inc., 2014). In Table 3, we present the parameter estimates for each level of each included attribute based on the total sample, that is, without distinguishing between the two different designs of the carbon footprint label. These parameters are usually interpreted as the coefficients of utility associated with each attribute level, or "part-worths". The analysis revealed that the main effects of all included attributes are highly significant $(p<.0001)$, thus confirming that the carbon footprint label, as well as the price, the organic label, and the certifying organization, influenced participants' choice of a ground coffee product. This is consistent with Hypothesis 1.

\section{[Insert Table 3 around here]}

The span from highest to lowest part worth is a measure of that attribute's importance to consumers, given the range of the included attribute levels. Hence, it appears from Figure 2 that, given the price range, the price was the most important determinant of the choice of ground coffee, followed by the organic label and the carbon footprint. The certification organization responsible for the carbon label was least important for participants' choices among the varied attributes, perhaps because all three are well-respected organizations in each their category. Overall, the findings suggest that, among the available options, participants preferred low-priced organic coffee with a low carbon footprint, certified by Miljømærkning Danmark.

Hypotheses $\mathrm{H} 2-\mathrm{H} 4$ were tested the same way as $\mathrm{H} 1$, but by extending the model with interaction terms between carbon footprint and potentially moderating constructs. First, when the consumer's environmental concern is included in the model as a moderating variable, the interaction term with carbon footprint is highly significant (L-R ChiSquare $=22.994,2$ d.f., $\mathrm{p}<.0001$ ), consistent with the proposition that the importance of the carbon footprint depends on the consumer's environmental concern (Hypothesis 2). In order to illustrate this interaction effect graphically, we estimated the part worths for carbon footprint separately for consumers with high, medium and low environmental concern (Figure 2). 


\section{[Insert Figure 2 around here]}

As illustrated in Figure 2, the interaction between environmental concern and carbon footprint has the expected direction. Among those participants with the highest environmental concern, a low carbon footprint has a substantially higher, and a high carbon footprint a substantially lower part worth than an intermediate carbon footprint and than for participants with lower environmental concern. Among participants with intermediate environmental concern, the pattern is the same as for those with highest environmental concern, but the range of part worths is narrower, showing that carbon footprint is less important for these consumers' choices. Among participants with the lowest environmental concern, the range of part worths is even narrower and the pattern is radically different, the intermediate level of carbon emissions having the highest part worth. This shows that carbon footprint is of no practical importance for the consumers with the lowest environmental concern.

In order to test Hypothesis 3, another extended choice analysis was run, including experimental group (Original Carbon Trust label vs. Traffic light colored label) as a moderator of the impact of the carbon label. Consistent with the hypothesis, when experimental group is included in the model as a moderating variable, the interaction between carbon footprint and experimental group is statistically significant (L-R ChiSquare $=5.835,2 \mathrm{df}$., $\mathrm{p}=.05$ ). As shown in Figure 3, when using traffic light colors to stress the product's relative carbon footprint, the effect of the carbon footprint label on participants' choice of coffee is amplified. The part worth for the product with the lowest emission increased from 0.36, when the original Carbon Trust label was used, to 0.57, when a traffic light colored label was used, and the part worth for the product with the lowest emission decreased a similar amount. These results confirm that the impact of a carbon footprint label on consumers' choices depends on the design of the label and in the predicted way.

[Insert Figure 3 around here]

\section{Discussion}

Consistent with earlier studies reporting favorable consumer responses to carbon footprint labeling (Gadema and Oglethorpe, 2011; Vanclay et al., 2011; Vlaeminck et al., 2014), the present study found that a carbon footprint label significantly influences consumers' choices of a fast-moving consumer good (ground coffee), thus lending further support to the relevance of carbon footprint labeling. A carbon footprint label is more useful for consumers the more important a goal it is for them to protect the environment. This is reflected in prior research finding a positive relationship between pro-environmental attitudes and paying attention to eco-labels (Thøgersen, 2000). Consistent with this research, this study found that the impact of the carbon footprint label on consumer choices depends on the consumer's environmental concern. The more environmentally concerned participants were, the more important the carbon footprint label was for their choice of a package of ground coffee. This finding rules out the possibility that the found labeling effects are due to a misunderstanding of the label and, therefore, it strengthens the face validity of the key findings.

Be that as it may, previous research has found quite modest effects of carbon footprint labeling in practice; a finding that has primarily been attributed to the meaning of the information communicated by the label being incomprehensible to the average consumer (Hornibrook et al., 2015). On this backcloth, the key contribution of this study is its comparison of the effectiveness of the carbon footprint label originally designed by British Carbon Trust and an extended version of this label, adding traffic light colors to communicate the product's relative performance, as 
suggested, for example, by Grankvist et al. (2004). The reported experiment confirmed that when the carbon footprint label is extended with a traffic light color ranking, its effect on consumer choices is further amplified, leading to a larger shifting of consumer choices towards relatively lowcarbon products and away from relatively carbon-intensive ones.

Labeling products with traffic light colors implies ranking products of the same type, for example ground coffee or apples. Obviously, such a comparative labeling is limited to helping consumers to identify the worst and best alternatives within such a given product category. Limiting the comparability to the product category is necessary in practice, but it means that the traffic light colors cannot be used to steer consumer choices away from carbon intensive product categories, such as beef or cars. For this purpose, the absolute carbon emissions, as appearing at the original Carbon Trust label, may still be helpful, although extremely demanding.

Grankvist et al. (2004) suggested a moderating effect of environmental concern on the impact of an eco-label using a traffic light ranking. In terms of our experiment, this suggestion might imply a three-way interaction between carbon label, experimental group, and environmental concern. We tested this proposition (while controlling for the two-level interactions), but did not find a significant three-way interaction (see also Van Dam and De Jonge, 2015). ${ }^{1}$ This suggests that extending a carbon footprint label with a traffic light ranking might have a positive effect irrespective of consumers' environmental concern. However, our inability to detect a significant three-way interaction in this study might also be due to the small sample size, so further research is needed on this point.

Among the included product attributes, the price was found to be the most important for the choice of ground coffee. Despite many consumers appearing to be willing to pay a premium for environmentally friendly products, when the premium becomes increasingly large only the most environmentally concerned and/or economically capable consumers remain loyal (Blend and Ravenswaay, 1999; Sörqvist et al., 2015; Vecchio and Annunziata, 2015). However, it is possible that the price effect was amplified in this study due to the preponderance of young people with a low income in the sample.

The finding that the organic label was the second most important determinant of consumer choices is consistent with the general popularity of organic food in the studied market and with market info saying that organic coffee has a market share of about seven percent. The organic label and the carbon footprint label both appeal to environmentally concerned consumers. The finding that the organic label had a bigger impact on choices than the carbon footprint label may be due to the former being very well known in this market while the latter has not yet been implemented.

The implementation of a reliable carbon footprint-labeling program involves measuring and verifying the carbon emissions of a product throughout its lifecycle (Cohen and Vandenbergh, 2012). In principle, by means of Life Cycle Analysis (LCA), the carbon emissions of a product from the production of inputs to its final consumption and the disposal of waste are added up (Brenton et al., 2009). This procedure is obviously costly and it demands the conscientious cooperation of many companies and organizations. For this and other reasons, LCA in practice involves numerous assumptions, compromises and limitations, especially with regard to postpurchase carbon footprinting. Measuring post-purchase carbon emissions is especially problematic as they depend on how the product is handled by the consumer. For example, whether the consumer recycles a recyclable or partly recyclable product can significantly impact its real environmental friendliness.

\footnotetext{
${ }^{1}$ This calculation is not reported, but it can be acquired from the first author.
} 


\subsection{Limitations and future research}

This study suffers from the usual limitations of studies based on self-reported survey data collected in a situational environment that differs substantially from a real purchasing situation. Despite the choice experiment, what we reported in this study is stated rather than revealed preferences. Hence, reservations are needed especially with regard to the found absolute impact of the carbon footprint label. However, the core finding of this study - that adding traffic light colors to the carbon footprint label amplifies its effect on choices - is less sensitive to this limitation.

One of the artificial characteristics of the choice experiment was that the number of product attributes and their variation were smaller than in reality. In a real purchasing situation, attributes such as taste (quality), brand, the Fair Trade label, and coffee blend would compete with the proposed carbon footprint label for the consumer's attention. As a result, the calculated effect of the carbon footprint label (and other included attributes) might be inflated. Further, in a real purchasing situation, at least some of the attributes would vary more (i.e., have more levels) than in this experiment. Specifically, the carbon footprint of individual product alternatives would most likely have more than three levels, which would make this information more confusing and more difficult to comprehend for the average consumer. As a result, especially the calculated effect of the original Carbon Trust label might be inflated. However, this would then logically mean that the additional effect of extending the label with traffic light colors - the key proposition of the present study - is underestimated.

As with the price range, the range of $\mathrm{CO} 2$-emissions chosen for the experiment might influence the importance of this attribute for consumer choices. Hence, it is a limitation of this study that, as opposed to the price, information about the actual range of $\mathrm{CO} 2$-emissions is not available. However, one may speculate that the absolute range of $\mathrm{CO} 2$-emissions most likely has less implications for the importance of this attribute than, for example, for the price, because participating consumers were unfamiliar with carbon footprint information and because the carbon footprint of a product does not have any short-term personal implications.

Before completing the choice tasks, participants were presented with a short explanatory text about the proposed carbon footprint label, which may have activated environmental attitudes among participants with accessible attitudes toward the environment. This may have amplified the impact of the carbon footprint on choices, especially among consumers with strong environmental concern. Such an amplification effect should not necessarily be considered a bias, though. Rather, the short explanatory text about the proposed carbon footprint label may be considered a simulation of the communication campaign that would always accompany the introduction of a new eco-label. However, in reality it would take quite a while before even environmentally unconcerned consumers have paid similar attention to the messages of such a communication campaign as participants in this study presumably did to the explanatory text.

\section{Conclusions and implications}

This study examined the impact of a carbon footprint label on consumers' choice of a ground coffee product, a fast-moving consumer good, and specifically the impact of extending such a label with traffic light colors communicating the product's relative performance in its category. The study confirmed previous research finding a significant impact of a carbon footprint label on participants' choices of everyday consumer products. A carbon footprint label informs consumers about the emissions to the air that a given product is responsible for, typically indicated in grams of carbon (equivalents). Hence, carbon footprint labeling allows consumers to screen out carbon-intensive products and to identify low-carbon product alternatives. However, the meaning of grams of carbon 
dioxide can be difficult to comprehend for the average consumer. In order to understand such label information correctly, the consumer needs a lot of background knowledge about typical carbon emissions in the product group or at least to compare the available product alternatives on offer on this dimension; a level of deliberation, which rarely occurs when buying everyday consumer products. This makes it likely that such a label is often overlooked or ignored in practice.

In an effort to enhance the effectiveness of a carbon footprint label of the type introduced by British Carbon Trust in 2007, we here propose to extend the label with traffic light colors, ranking competing products in three categories according to their embedded carbon emissions. This study confirmed that a simple three-tier traffic light ranking significantly amplifies the effect of carbon footprint labeling on consumer choices. Just adding traffic light colors reflecting the relative carbon footprint within a product category led to a further shift of consumer choices away from relatively carbon-intensive alternatives towards relatively low-carbon ones. Eco-labels and their design are important elements of the "choice architecture" of everyday consumer choices (Ölander and Thøgersen, 2014). Arguably, in some contexts, simple "nudges," such as simplifying the consumer's choice task, as proposed here, can have larger effects than much more coersive interventions, even significant economic incentives (Sunstein, 2016).

Voluntary eco-labels come at a financial cost to the producer, which is sent on to the consumer as a price premium (Grankvist et al., 2004). It seems unlikely that producers would voluntarily have their product labeled with a red label indicating that it performs worse than average in terms of $\mathrm{CO}_{2}$ emissions. Therefore, in order to implement a carbon footprint label, such as the one proposed here, either legal regulation or strong retailer commitment is required. The legal regulation should make it mandatory to classify and label all products according to the three categories. This would be similar to the mandatory labeling of a range of energy consuming consumer products in the EU, disclosing the energy consumption of the product during use (also) relative to others in the same product category. The well-known EU energy labeling classifies products in seven categories, using both letters (originally from A to $\mathrm{G}$ ) and traffic light colors to communicate the product's relative energy performance.

A mandatory three-tier traffic light color scheme would allow any company that is not labeled red to differentiate and dissociate their products from the environmentally harmful ones (Van Dam and De Jonge, 2015). Furthermore, negatively labeled products might spur environmentally friendly product innovation and drive environmentally harmful products out of the market, if consumers avoid the red-labeled products (Grankvist et al., 2004). This dynamics has been observed with the EU Energy label, where the ranking scale has had to be revised (which was unfortunately done by adding +'s to the A-label, cf. Heinzle and Wüstenhagen, 2012; Ölander and Thøgersen, 2014), as too many products were ranked in the best category.

Tesco's (former) carbon footprint labeling is an example of retailer commitment, as they originally planned to label all products sold in their stores. This resulted in over 1,100 products being carbon footprint labeled, but only with absolute carbon emissions, as explained earlier. However, the fact that even a big and committed retailer like Tesco gave up suggests that it would most likely require governmental regulation to ensure a widespread and simultaneous uptake of such a scheme (Gadema and Oglethorpe, 2011).

In conclusion, a carbon footprint label and especially a label fortified with a traffic light classification could be a useful tool to direct consumer choices toward low-carbon products and ultimately reduce the negative impact of consumption on the environment. A carbon footprint label with traffic light classification not only allows consumers to use simple heuristics to identify low carbon products (choose green, avoid red), but similarly to judge and compare carbon emissions 
across product categories through consulting the emitted grams of carbon. Thus, such a label would be useful for both deliberate and spontaneous decision-making (Kahneman, 2011).

Note that a carbon footprint label is not a substitute for existing eco-labeling schemes, but a possible addition. Accounting for the carbon emissions of a product is only one of many critical environmental factors that consumers should consider when purchasing everyday products (Steffen et al., 2015).

\section{References}

Berlingske Business, 2012. Markedsrapport: Eksplosiv vækst i salget af kaffe.

Blend, J.R., Ravenswaay, E.O.v., 1999. Measuring consumer demand for ecolabeled apples. American Agricultural Economics Association 81, 1072-1077.

Boardman, B., 2008. Carbon labelling: too complex or will it transform our buying? Significance 5, 168-171.

Brenton, P., Edwards-Jones, G., Jensen, M.F., 2009. Carbon labelling and low-income country exports: A review of the development issues. Development Policy Review 27, 243-267.

Carbon Trust, 2012. Creating change through carbon footprinting.

Cohen, M.A., Vandenbergh, M.P., 2012. The potential role of carbon labeling in a green economy. Energy Economics 34, Supplement 1, S53-S63.

De Pelsmacker, P., Janssens, W., Sterckx, E., Mielants, C., 2006. Fair-trade beliefs, attitudes and buying behaviour of Belgian consumers. International Journal of Nonprofit and Voluntary Sector Marketing 11, 125-138.

European Commission, 2009. Europeans' attitudes towards the issue of sustainable consumption and production, Flash Eurobarometer. Office for Official Publications of the European Communities, Luxembourg.

Evans, A.N., Rooney, B.J., 2014. Methods in psychological research (3e). Sage, Thousand Oaks, CA.

Fiske, S.T., 1980. Attention and weight in person perception: The impact of negative and extreme behaviour. Journal of Personality and Social Psychology 38, 889-906.

Gadema, Z., Oglethorpe, D., 2011. The use and usefulness of carbon labelling food: A policy perspective from a survey of UK supermarket shoppers. Food Policy 36, 815-822.

Grankvist, G., Dahlstrand, U., Biel, A., 2004. The impact of environmental labeling on consumer preference: Negative versus positive labels. Journal of Consumer Policy 27, 213-230.

Grunert, K.G., Wills, J.M., 2007. A review of European research on consumer response to nutrition information on food labels. Journal of Public Health 15, 385-399. 
Heinzle, S.L., Wüstenhagen, R., 2012. Dynamic adjustment of eco-labeling schemes and consumer choice - the revision of the EU energy label as a missed opportunity? Business Strategy and The Environment 21, 60-70.

Hensher, D.A., Rose, J.M., Greene, W.H., 2005. Applied choice analysis: a primer. Cambridge University Press, Cambridge.

Hornibrook, S., May, C., Fearne, A., 2015. Sustainable development and the consumer: Exploring the role of carbon labelling in retail supply chains. Business Strategy and the Environment 24, 266276.

Ito, T.A., Larsen, J.T., Smith, N.K., Cacioppo, J.T., 1998. Negative information weighs more heavily on the brain: The negativity bias in evaluative categorizations. Journal of Personality and Social Psychology 75, 887-900.

Johnson, F.R., Lancsar, E., Marshall, D., Kilambi, V., Mühlbacher, A., Regier, D.A., Bresnahan, B.W., Kanninen, B., Bridges, J.F.P., 2013. Constructing experimental designs for discrete-choice experiments: Report of the ISPOR conjoint analysis experimental design good research practices task force. Value in Health 16, 3-13.

Johnson, R., Orme, B., 2003. Getting the most from CBC, Sawtooth Research Paper Series. Sawtooth.

Kahneman, D., 2011. Thinking, fast and slow. Macmillan, New York, NY.

Kahneman, D., Tversky, A., 1979. Prospect theory: An analysis of decision making under risk. Econometrica 47, 263-291.

Kimura, A., Wada, Y., Kamada, A., Masuda, T., Okamoto, M., Goto, S.-i., Tsuzuki, D., Cai, D., Oka, T., Dan, I., 2010. Interactive effects of carbon footprint information and its accessibility on value and subjective qualities of food products. Appetite 55, 271-278.

Kuhfeld, W.F., 2005. Marketing research methods in SAS: Experimental design, choice, conjoint, and graphical techniques. SAS Institute Inc., Cary, NC.

Marshall, D., Bridges, J.P., Hauber, B., Cameron, R., Donnalley, L., Fyie, K., Reed Johnson, F., 2010. Conjoint analysis applications in health - How are studies being designed and reported? Patient-Patient-Centered-Outcome-Res 3, 249-256.

Ministeriet for Fødevarer Landbrug og Fiskeri, 2014. Klimatabel.

Økologisk Landsforening, 2014. Økologisk markedsnotat (organic market brief). Økologisk Landsforening, Århus.

Ölander, F., Thøgersen, J., 2014. Informing versus nudging in environmental policy. Journal of Consumer Policy 37, 341-356.

Orme, B., 2003. Special features of CBC software for packaged goods and beverage research, Research Paper Series. Sawtooth Software. 
Prakash, A., 2002. Green marketing, public policy and managerial strategies. Business Strategy and the Environment 11, 285-297.

Reisch, L.A., Sunstein, C.R., 2015. Behavioral economics and consumption. The Wiley Blackwell Encyclopedia of Consumption and Consumer Studies 1-2.

Rose, J.M., Bliemer, M.C.J., 2009. Constructing efficient stated choice experimental designs. Transport Reviews 29, 587-617.

Sammer, K., Wüstenhagen, R., 2006. The influence of eco-labelling on consumer behavior Results of a discrete choice analysis for washing machines. Business Strategy and the Environment $15,185-199$.

SAS Institute Inc., 2014. JMP® 11 Consumer Research. SAS Institute Inc, Cary, NC.

Sörqvist, P., Haga, A., Langeborg, L., Holmgren, M., Wallinder, M., Nöstl, A., Seager, P.B., Marsh, J.E., 2015. The green halo: Mechanisms and limits of the eco-label effect. Food Quality and Preference 43, 1-9.

Steffen, W., Richardson, K., Rockström, J., Cornell, S.E., Fetzer, I., Bennett, E.M., Biggs, R., Carpenter, S.R., de Vries, W., de Wit, C.A., 2015. Planetary boundaries: Guiding human development on a changing planet. Science $347,1259855$.

Sunstein, C.R., 2016. The council of psychological advisers. Annual Review of Psychology 67, 713-737.

Teisl, M.F., Rubin, J., Noblet, C.L., 2008. Non-dirty dancing? Interactions between eco-labels and consumers. Journal of Economic Psychology 29, 140-159.

Thaler, R.H., Sunstein, C.R., 2008. Nudge. Improving decisions about health, wealth and happiness. Penguin Books, London, UK.

Thøgersen, J., 2000. Psychological determinants of paying attention to eco-labels in purchase decisions: Model development and multinational validation. Journal of Consumer Policy 23, 285313.

Thøgersen, J., 2005. Consumer behaviour and the environment: Which role for information?, in: Krarup, S., Russell, C.S. (Eds.), Environment, information and consumer behaviour. Edward Elgar, Cheltenham, UK, pp. 51-63.

Thøgersen, J., Haugaard, P., Olesen, A., 2010. Understanding consumer responses to ecolabels. European Journal of Marketing 44, 1787 - 1810.

Thøgersen, J., Jørgensen, A.-K., Sandager, S., 2012. Consumer decision making regarding a "green" everyday product. Psychology \& Marketing 29, 187-197.

Tobler, C., Visschers, V.H.M., Siegrist, M., 2011. Eating green. Consumers' willingness to adopt ecological food consumption behaviors. Appetite 57, 674-682. 
Upham, P., Dendler, L., Bleda, M., 2011. Carbon labelling of grocery products: public perceptions and potential emissions reductions. Journal of Cleaner Production 19, 348-355.

Van Dam, Y., De Jonge, J., 2015. The positive side of negative labelling. Journal of Consumer Policy 38, 19-38.

Van Loo, E.J., Caputo, V., Nayga Jr, R.M., Verbeke, W., 2014. Consumers' valuation of sustainability labels on meat. Food Policy 49, Part 1, 137-150.

Vanclay, J., Shortiss, J., Aulsebrook, S., Gillespie, A., Howell, B., Johanni, R., Maher, M.,

Mitchell, K., Stewart, M., Yates, J., 2011. Customer response to carbon labelling of groceries.

Journal of Consumer Policy 34, 153-160.

Vaughan, A., 2012. Tesco drops carbon-label pledge, The Guardian.

Vecchio, R., Annunziata, A., 2015. Willingness-to-pay for sustainability-labelled chocolate: An experimental auction approach. Journal of Cleaner Production 86, 335-342.

Verma, R., Iqbal, Z., Plaschka, G., 2004. Safeguarding your customers: The guest's view of hotel security. California Management Review 46, 43-67.

Vlaeminck, P., Jiang, T., Vranken, L., 2014. Food labeling and eco-friendly consumption:

Experimental evidence from a Belgian supermarket. Ecological Economics 108, 180-190.

Wiedmann, T., Minx, J., 2007. A definition of 'carbon footprint'. Ecological Economics Research Trends 2, 55-65. 
Table 1. Socio-demographic characteristics of the sample, distribution in percentages

\begin{tabular}{lr}
\hline & Pct. \\
\hline Group 1 & 52 \\
Group 2 & 48 \\
Age & 31 \\
$18-24$ & 49 \\
$25-34$ & 4 \\
$35-44$ & 12 \\
$45-54$ & 4 \\
$55+$ & \\
Education & 1 \\
Elementary school & 1 \\
Vocational training & 17 \\
High school & 12 \\
Associate degree & 25 \\
Bachelor's degree & 44 \\
Masters degree or above & \\
Income* & 63 \\
Low & 16 \\
Intermediate & 17 \\
High & \\
No answer & \\
\hline$*$ Income - & \\
\hline
\end{tabular}

* Income - low: under 300,000 DKK, medium: between 300,000 and 700,000 DKK, high: over 700,000 DKK. 
Table 2. Discrete choice experiment design for coffee: Attributes and attribute levels

\begin{tabular}{lcll}
\hline Attribute & Levels & & \\
\hline Price (in DKK) & 32 & 38 & 44 \\
Organic Label & No & Yes & \\
Carbon Label & $210 \mathrm{~g}$ & $150 \mathrm{~g}$ & $90 \mathrm{~g}$ \\
Certification Organization & Coop & WWF & Miljømærkning Danmark \\
\hline
\end{tabular}


Table 3. Attribute-level part worths for the attributes included in the discrete-choice model $(N=$ 137)

\begin{tabular}{llccrc}
\hline Attribute & Level & Part worths & L-R ChiSquare & D.f. & $\mathrm{p}$ \\
\hline Price (in DKK) & 32 & .80 & 303.716 & 2 & $<.0001$ \\
& 38 & -.04 & & & \\
Organic Label & 44 & -.76 & & & \\
& No & & & & \\
Carbon Footprint Label & Yes & -.68 & 338.365 & 1 & $<.0001$ \\
& $210 \mathrm{~g}$ & .68 & & & \\
& $150 \mathrm{~g}$ & -.47 & 85.418 & 2 & $<.0001$ \\
& $90 \mathrm{~g}$ & .01 & & & \\
Certification Organization & Coop & .46 & & & \\
& WWF & -.28 & 32.741 & 2 & $<.0001$ \\
& Miljømærkning & .07 & & & \\
& Danmark & .21 & & & \\
\hline
\end{tabular}




\section{Figure captions}

Figure 1. Examples of product profiles presented to Group 1 and Group 2.

Figure 2. Carbon footprint part worths for consumers at three levels of environmental concern: low, medium and high.

Figure 3. Separate carbon footprint part worths for consumers in Group 1 (the Carbon Trust label) and Group 2 (the modified Carbon Trust label with traffic light colors). 
Group 1

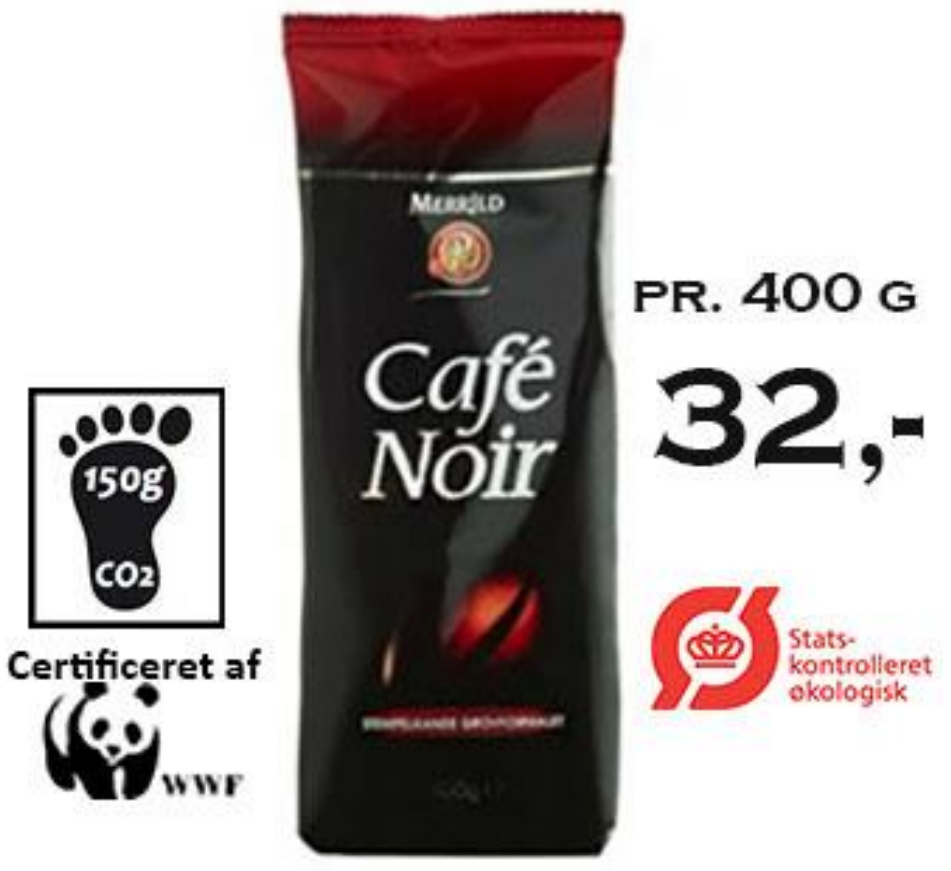

Group 2

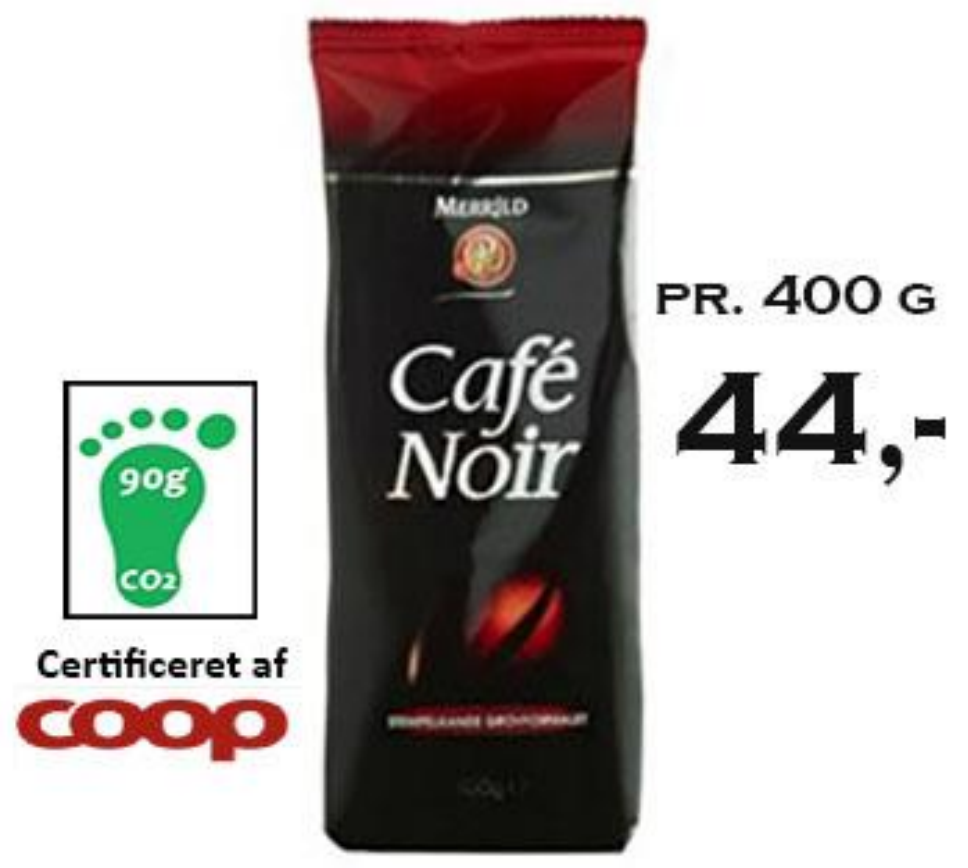

Figure 1. 
Figure 2.

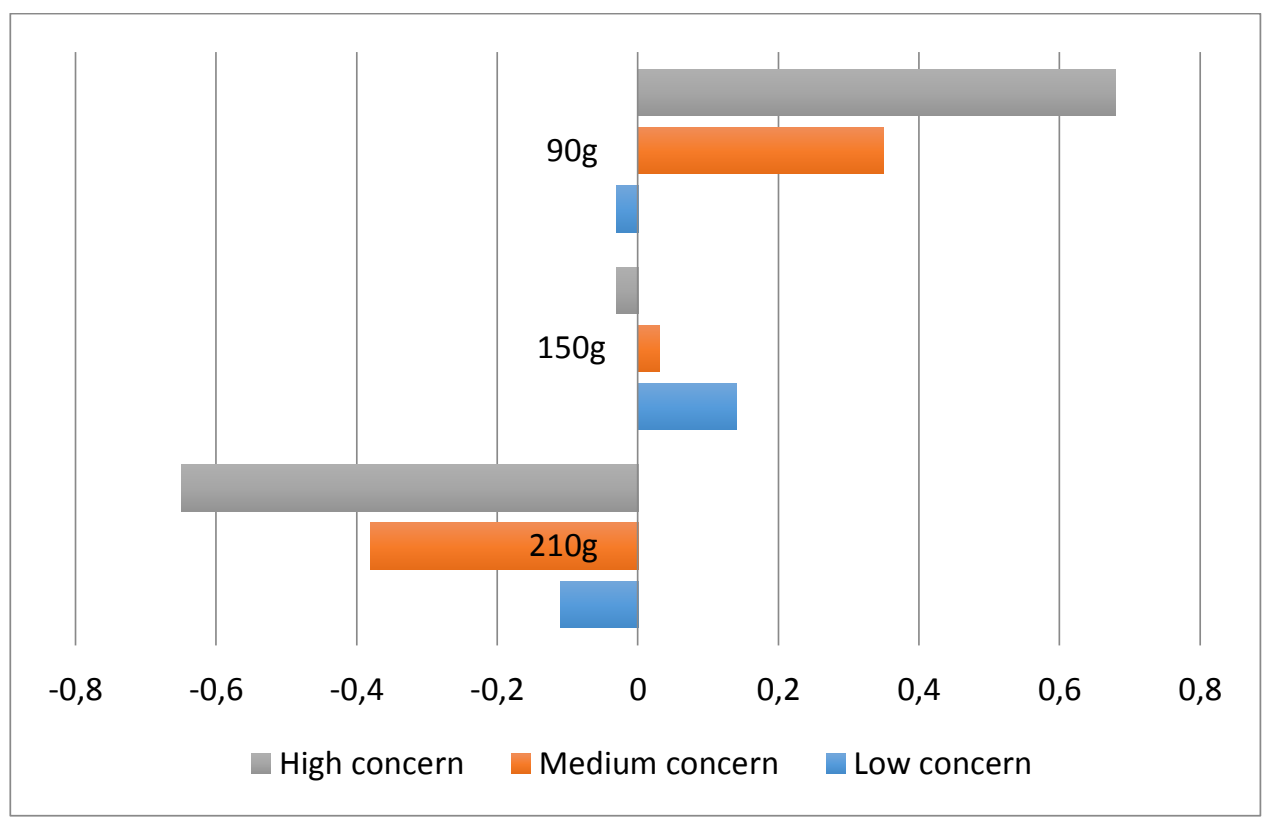


Figure 3.

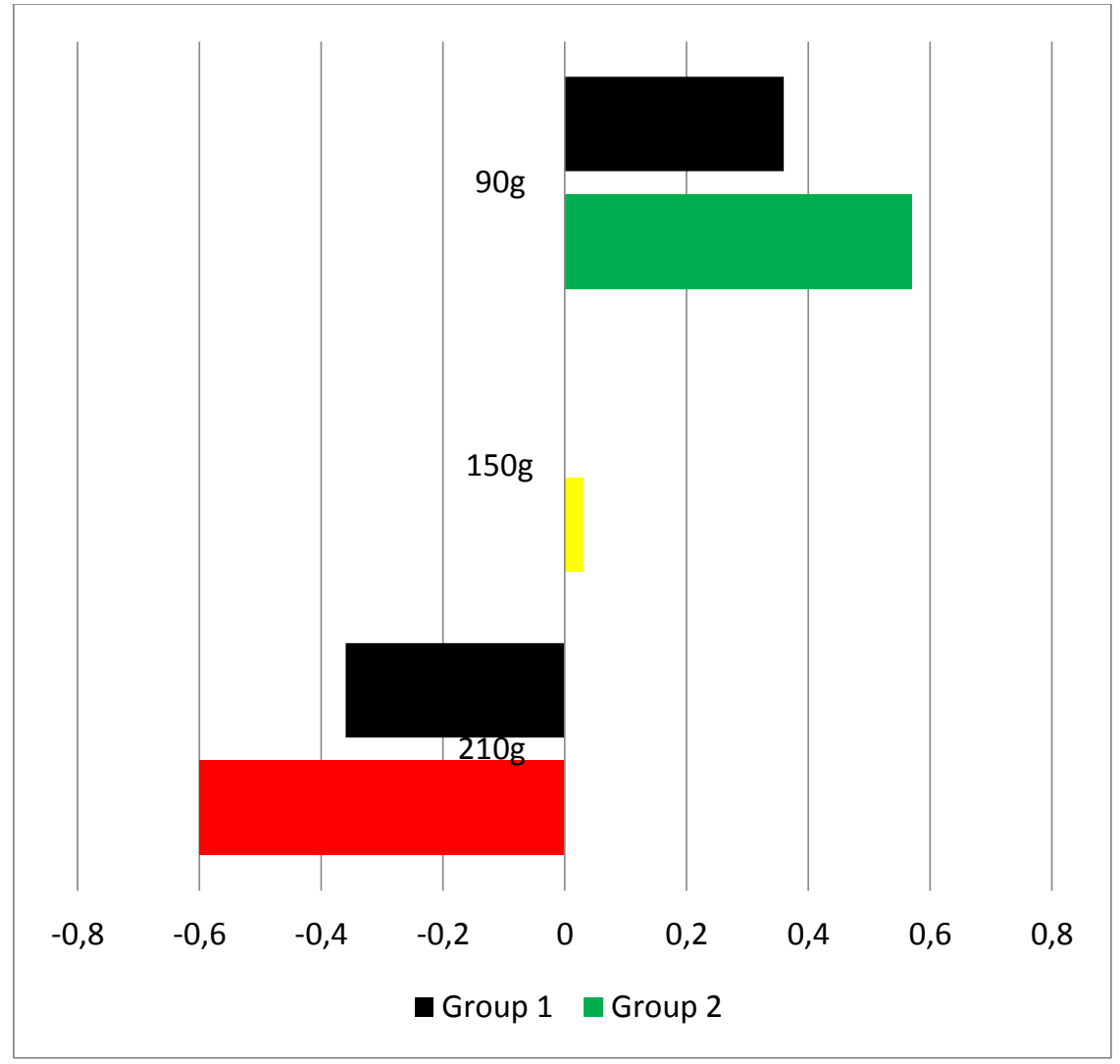

